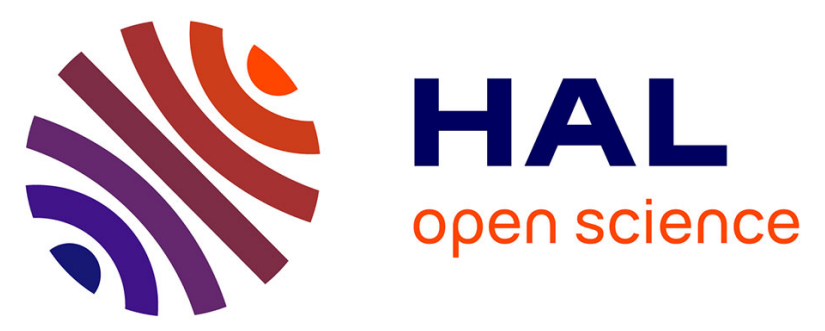

\title{
Long-term consequences of maternal high-fat feeding on hypothalamic leptin sensitivity and diet-induced obesity in the offspring.
}

Jacqueline Férézou-Viala, Anne-France Roy, Daniel Gripois, Michel Parquet, Virginie Bailleux, Arieh Gertler, Bernadette Delplanque, Jean Djiane, Michel Riottot, Mohammed Taouis

\section{To cite this version:}

Jacqueline Férézou-Viala, Anne-France Roy, Daniel Gripois, Michel Parquet, Virginie Bailleux, et al.. Long-term consequences of maternal high-fat feeding on hypothalamic leptin sensitivity and dietinduced obesity in the offspring.. American Journal of Physiology, 2007, 293 (3), pp.R1056-1062. 10.1152/ajpregu.00117.2007 . hal-00413853

\section{HAL Id: hal-00413853 https://hal.science/hal-00413853}

Submitted on 30 May 2020

HAL is a multi-disciplinary open access archive for the deposit and dissemination of scientific research documents, whether they are published or not. The documents may come from teaching and research institutions in France or abroad, or from public or private research centers.
L'archive ouverte pluridisciplinaire HAL, est destinée au dépôt et à la diffusion de documents scientifiques de niveau recherche, publiés ou non, émanant des établissements d'enseignement et de recherche français ou étrangers, des laboratoires publics ou privés. 
Jacqueline Férézou-Viala, Anne-France Roy, Colette Sérougne, Daniel Gripois, Michel Parquet, Virginie Bailleux, Arieh Gertler, Bernadette Delplanque, Jean Djiane, Michel Riottot and Mohammed Taouis

Am J Physiol Regulatory Integrative Comp Physiol 293:1056-1062, 2007. First published Jun 6, 2007; doi:10.1152/ajpregu.00117.2007

You might find this additional information useful...

This article cites 47 articles, 26 of which you can access free at:

http://ajpregu.physiology.org/cgi/content/full/293/3/R1056\#BIBL

This article has been cited by 10 other HighWire hosted articles, the first 5 are:

The Developmental Origins, Mechanisms, and Implications of Metabolic Syndrome

K. D. Bruce and M. A. Hanson

J. Nutr., March 1, 2010; 140 (3): 648-652.

[Abstract] [Full Text] [PDF]

Role of Early Hormonal and Nutritional Experiences in Shaping Feeding Behavior and Hypothalamic Development

S. G. Bouret

J. Nutr., March 1, 2010; 140 (3): 653-657.

[Abstract] [Full Text] [PDF]

The Epigenetics of Sex Differences in the Brain

M. M. McCarthy, A. P. Auger, T. L. Bale, G. J. De Vries, G. A. Dunn, N. G. Forger, E. K.

Murray, B. M. Nugent, J. M. Schwarz and M. E. Wilson

J. Neurosci., October 14, 2009; 29 (41): 12815-12823.

[Abstract] [Full Text] [PDF]

Maternal and postweaning diet interaction alters hypothalamic gene expression and modulates response to a high-fat diet in male offspring

K. C. Page, R. E. Malik, J. A. Ripple and E. K. Anday

Am J Physiol Regulatory Integrative Comp Physiol, October 1, $2009 ; 297$ (4): R1049-R1057.

[Abstract] [Full Text] [PDF]

Altered skeletal muscle insulin signaling and mitochondrial complex II-III linked activity in adult offspring of obese mice

P. Shelley, M. S. Martin-Gronert, A. Rowlerson, L. Poston, S. J. R. Heales, I. P. Hargreaves, J. M. McConnell, S. E. Ozanne and D. S. Fernandez-Twinn

Am J Physiol Regulatory Integrative Comp Physiol, September 1, 2009; 297 (3): R675-R681.

[Abstract] [Full Text] [PDF]

Updated information and services including high-resolution figures, can be found at:

http://ajpregu.physiology.org/cgi/content/full/293/3/R1056

Additional material and information about American Journal of Physiology - Regulatory, Integrative and Comparative Physiology can be found at:

http://www.the-aps.org/publications/ajpregu

This information is current as of September 7, 2010 .

The American Journal of Physiology - Regulatory, Integrative and Comparative Physiology publishes original investigations that illuminate normal or abnormal regulation and integration of physiological mechanisms at all levels of biological organization, ranging from molecules to humans, including clinical investigations. It is published 12 times a year (monthly) by the American

Physiological Society, 9650 Rockville Pike, Bethesda MD 20814-3991. Copyright @ 2007 by the American Physiological Society. ISSN: 0363-6119, ESSN: 1522-1490. Visit our website at http://www.the-aps.org/. 


\title{
Long-term consequences of maternal high-fat feeding on hypothalamic leptin sensitivity and diet-induced obesity in the offspring
}

\author{
Jacqueline Férézou-Viala, ${ }^{1,2,3}$ Anne-France Roy, ${ }^{1,2}$ Colette Sérougne, ${ }^{1,2,4}$ Daniel Gripois, ${ }^{1,2}$ \\ Michel Parquet, ${ }^{1,2,3}$ Virginie Bailleux,${ }^{1,2}$ Arieh Gertler, ${ }^{5}$ Bernadette Delplanque, ${ }^{1,2,3}$ Jean Djiane, ${ }^{1,2}$ \\ Michel Riottot, ${ }^{1,2,4}$ and Mohammed Taouis ${ }^{1,2}$ \\ ${ }^{1}$ Université Paris-Sud, UMR 1197, Neurobiologie de l'Olfaction et de la Prise Alimentaire, Neuroendocrinologie Moléculaire \\ de la Prise Alimentaire, Orsay; ${ }^{2}$ Institut National de la Recherche Agronomique, UMR 1197, Jouy-en-Josas; ${ }^{3}$ Institut \\ National de la Santé et de la Recherche Médicale, Orsay; ${ }^{4}$ Centre National de la Recherche Scientifique, Orsay, France; \\ and ${ }^{5}$ The Hebrew University of Jerusalem, Rehovot, Israel
}

Submitted 15 February 2007; accepted in final form 5 June 2007

Férézou-Viala J, Roy A-F, Sérougne C, Gripois D, Parquet M, Bailleux V, Gertler A, Delplanque B, Djiane J, Riottot M, Taouis M. Long-term consequences of maternal high-fat feeding on hypothalamic leptin sensitivity and diet-induced obesity in the offspring. Am J Physiol Regul Integr Comp Physiol 293: R1056-R1062, 2007. First published June 6, 2007; doi:10.1152/ajpregu.00117.2007.—Epidemiological and animal studies suggest that the alteration of hormonal and metabolic environment during fetal and neonatal development can contribute to development of metabolic syndrome in adulthood. In this paper, we investigated the impact of maternal high-fat (HF) diet on hypothalamic leptin sensitivity and body weight gain of offspring. Adult Wistar female rats received a $\mathrm{HF}$ or a control normal-fat (C) diet for $6 \mathrm{wk}$ before gestation until the end of the suckling period. After weaning, pups received either $\mathrm{C}$ or $\mathrm{HF}$ diet during $6 \mathrm{wk}$. Body weight gain and metabolic and endocrine parameters were measured in the eight groups of rats formed according to a postweaning diet, maternal diet, and gender. To evaluate hypothalamic leptin sensitivity in each group, STAT-3 phosphorylation was measured in response to leptin or saline intraperitoneal bolus. Pups exhibited similar body weights at birth, but at weaning, those born to $\mathrm{HF}$ dams weighed significantly less $(-12 \%)$ than those born to $\mathrm{C}$ dams. When given the HF diet, males and females born to HF dams exhibited smaller body weight and feed efficiency than those born to $\mathrm{C}$ dams, suggesting increased energy expenditure programmed by the maternal HF diet. Thus, maternal HF feeding could be protective against adverse effects of the HF diet as observed in male offspring of control dams: overweight $(+17 \%)$ with hyperleptinemia and hyperinsulinemia. Furthermore, offspring of HF dams fed either $\mathrm{C}$ or $\mathrm{HF}$ diet exhibited an alteration in hypothalamic leptin-dependent STAT-3 phosphorylation. We conclude that maternal high-fat diet programs a hypothalamic leptin resistance in offspring, which, however, fails to increase the body weight gain until adulthood.

leptin resistance; hypothalamus; high-fat diet

OBESITY AND RELATED METABOLIC disorders are considered as a major health issue worldwide, and epidemiological data indicate that the prevalence to these diseases is dependent upon genetic, dietary, and lifestyle factors (2, 20, 29). Increasing evidence suggests that the risk of developing a metabolic syndrome may be influenced very early in the development, especially through inappropriate fetal and/or neonatal nutrition $(8,28,33,43)$. The process by which factors acting during early life and having a long-term effect in adults is called

Address for reprint requests and other correspondence: J. Férézou, NMPAUMR 1197, Bât 447, Université Paris-Sud, F-91 405-Orsay Cedex, France (e-mail: jacqueline.ferezou@u-psud.fr). programming, and it is now considered as a potential mechanism that contributes to the development of obesity $(11,19)$. To understand the mechanisms underlying this developmental programming, various animal models were used, in which hormonal and metabolic prenatal or postnatal environment has been altered through changes in maternal nutritional status (1). The most documented one is the rodent model of drastic maternal undernutrition which was extensively used to examine the susceptibility of the offspring to develop obesity, hypertension, and diabetes in adulthood $(7,44)$. While fetal undernutrition leads to programming of metabolism and an adult phenotype that is adapted to poor nutrition, the exposition to abundant dietary conditions later in life will then initiate the development of obesity $(40,45)$. This model fits with the "thrifty phenotype" hypothesis to explain the predisposition of low weight newborns to become overweight in the adult life (17). Such an effect has been initially observed in adult men conceived during the Dutch famine in 1944-1945, whose mothers were undernourished during pregnancy (35). Furthermore, clinical observations suggest that both maternal obesity and gestational diabetes may also predispose the fetus to develop a metabolic syndrome later in life $(14,31,34)$. Similarly in rodents, maternal high-fat diet during pregnancy and lactation results in a phenotype of the offspring close to the human metabolic syndrome $(1,15,16,42)$.

In rodents, the fetal programming has been partly explained by recent studies showing that leptin (10), an adipose-tissue secreted anorexic cytokine, acts as a neurotrophic factor during brain development, besides its key role in the regulation of food intake $(6,37)$. Leptin regulates energy homeostasis and food intake through its action in specific hypothalamic nuclei (9). In the arcuate nucleus, leptin binds to its long isoform receptor $(\mathrm{ObRb})$, which is phosphorylated through the activation of JAK-2, leading to the association and the phosphorylation of the transcription factor STAT-3. Phosphorylated STAT-3 is then translocated to the nucleus, where it regulates the expression of several neuropeptides involved in the control of food intake such as proopiomelanocortin (POMC) (anorexigenic peptide) and neuropeptide Y (NPY) (orexigenic peptide) $(5,22)$. Thus, leptin activates the expression of POMC and inhibits that of NPY $(36,39)$. Interestingly, recent studies clearly indicate that a lack of leptin during early life in mouse

The costs of publication of this article were defrayed in part by the payment of page charges. The article must therefore be hereby marked "advertisement" in accordance with 18 U.S.C. Section 1734 solely to indicate this fact. 
compromises the neuronal organization of hypothalamic nuclei involved in food intake control (6), affecting then the sensitivity to this hormone in adulthood. This may explain, at least partially, the development of obesity in adult rodents born to hypoleptinemic dams due to feed-restriction during the gestational period.

Taken together, these data indicate that undernutrition or overnutrition during pregnancy alters fetal hormonal and metabolic environment, leading to the development of metabolic disorders associated with leptin resistance in offspring $(15,38)$. The maternal undernutrition model has been extensively used in rodents to obtain programmed offspring prone to dietinduced obesity. In the present paper, we used a nutritional model that is closer to the human modern lifestyle characterized by a high-fat and -energy diet to investigate its potential impact on the metabolic imprinting of offspring. This was achieved by subjecting adult female rats to a high-fat (HF) or a control normal-fat (C) diet before mating and during pregnancy and lactation. The offspring of each group was then fed $\mathrm{HF}$ or $\mathrm{C}$ diet until adulthood. The body weight gain, energy intake, as well as plasma lipid and hormonal parameters, were measured in all offspring groups. The hypothalamic leptin sensitivity was also assessed in each group, by measuring leptin-dependent STAT-3 phosphorylation. We show that adult male offspring born to control dams and fed a HF diet exhibited an increased body weight, with hypothalamic leptin resistance, but not female offspring. Conversely, offspring born to $\mathrm{HF}$ dams and fed $\mathrm{C}$ or HF diet exhibited hypothalamic leptin resistance, without significant increase in body weight.

\section{MATERIALS AND METHODS}

Diets. Commercial pellets (formula 113, from Safe, Augy, France) and two semipurified diets, custom-made in our laboratory, were used. The composition of the HF diet was adapted from Guo and Jen (16) and that of the control (C) diet was similar to that of commercial pellets, which usually contain $4-5 \%$ fat. As shown in Table 1 , the hypercaloric HF diet only differed from the normal-fat $\mathrm{C}$ diet by more palm oil at the expense of starch.

Care and maintenance of animals. Animal studies were carried out in agreement with the French legislation on animal experimentation and with the authorization of the French Ministry of Agriculture (Animal Health and Protection Directorate).

Twenty-five 9-wk-old female and six male Wistar rats (from CER Janvier, Le Genest-St-Isle, France) were housed in individual cages under controlled temperature $\left(22 \pm 1{ }^{\circ} \mathrm{C}\right)$, with a 12 :12-h light-dark cycle (light on: 8:00 AM), and were given commercial pellets for 1 wk. Two groups of females were then formed according to the diet (control or high-fat). After $6 \mathrm{wk}$, females were caged in collective cages for mating and returned into individual cages after 9 days. Timing of delivery, litter size, and weight were recorded at birth. Litters were adjusted to 10 or 11 pups for each dam, while maintaining the sex ratio as close to $1: 1$ as possible. The whole litter weight was checked weekly, and the individual body weight of pups was registered at weaning, when aged 28 days. Eight groups of 12 pups were then formed and named according to the postweaning $\operatorname{diet}(\mathrm{C}$ or $\mathrm{H}$, as first letter for control or high-fat diet, respectively), maternal diet (C or $\mathrm{H}$ as 2 nd letter) and gender ( $\mathrm{m}$ or $\mathrm{f}$ as $3 \mathrm{rd}$ letter for male and female, respectively). Pups were allowed to free access to food and water. Body weights of adult females and their pups were measured twice a week. Food intake was monitored during the $6 \mathrm{wk}$ before mating for all females, and for the mid-4-wk of the postweaning period for pups. After $6 \mathrm{wk}$ on the $\mathrm{C}$ or HF diet, adult offspring (age: $10 \mathrm{wk}$ ) were fasted overnight and received by intraperitoneal injection of recom-
Table 1. Composition and energy content of the semi-purified normal-fat and high-fat diets

\begin{tabular}{lcc}
\hline \hline & $\mathrm{C}$ & $\mathrm{HF}$ \\
\hline Content, g/100 g starch & 47.5 & 12.5 \\
Sucrose & 15 & 15 \\
Casein & 20 & 20 \\
Palm oil* & 3 & 38 \\
Colza oil & 2 & 2 \\
Cellulose & 5 & 5 \\
Vitamins & 2.5 & 2.5 \\
Mineral mix & 5 & 5 \\
Energy (kcal\%) derived from & & \\
carbohydrates & $68.5 \dagger$ & $22.6 \ddagger$ \\
proteins & 19.6 & 12.9 \\
lipids & 11.9 & 64.5 \\
Energy content, kcal/100 g & 377.1 & 571.9 \\
\hline
\end{tabular}

* Rich in saturated fatty acids. $†$ The energy constituted by carbohydrates in this diet is $76 \mathrm{kcal} \%$ starch and $24 \mathrm{kcal} \%$ sucrose. $\$$ The energy constituted by carbohydrates in this diet is $45 \mathrm{kcal} \%$ starch and $55 \mathrm{kcal} \%$ sucrose. C, normal-fat diet; HF, high-fat diet.

binant ovine leptin $(1 \mathrm{mg} / \mathrm{kg})$ or physiological saline. After $30 \mathrm{~min}$, animals were killed by decapitation after cervical elongation. Blood was collected on heparin $(10 \mathrm{IU} / \mathrm{ml})$, and tissues (hypothalamus and liver) were quickly removed. The hypothalamus was immediately frozen into liquid nitrogen, and the liver was weighed.

Biochemical analyses. Chemicals were generally purchased from Sigma-Aldrich. Ovine leptin was produced in our laboratory, as previously described (13).

Plasma parameters determination. Plasma lipids were measured by enzymatic procedures using commercial kits (Biomerieux, Lyon, France) by means of an automatic analyzer (Abbott VP, Rungis, France): total cholesterol (RTU method), triglycerides, and phospholipids (PAP 150 method). Plasma glucose level was measured by enzymatic assay (Biochem Immunosystems, Aix-en-Provence, France). Insulin and leptin were assayed by radioimmunoassay using commercial diagnostic kits (Linco Research, St. Louis, MO). The homeostatic model assessment (HOMA) for insulin resistance (27) was calculated from insulin and glucose values using the HOMA 2 calculator software ver. 2.2 (Diabetes Trials Unit, University of Oxford, Cambridge, UK).

Western blot analysis. Samples were prepared as previously described (4). Briefly, frozen hypothalami were homogenized in lysis buffer: $10 \mathrm{mM}$ Tris $\cdot \mathrm{HCl}(\mathrm{pH} 7.5), 150 \mathrm{mM} \mathrm{NaCl}, 1 \mathrm{mM}$ EGTA, 1 mM EDTA, $0.5 \%$ nonidet-P40, $1 \%$ Triton $\mathrm{X}-100$, protease inhibitor cocktail (0.35 mg/ml PMSF, $2 \mu \mathrm{g} / \mathrm{ml}$ leupeptin, $2 \mu \mathrm{g} / \mathrm{ml}$ aprotinin), and phosphatase inhibitor cocktail $(10 \mathrm{mM}$ sodium fluoride, $1 \mathrm{mM}$ sodium orthovanadate, $20 \mathrm{mM}$ sodium $\beta$-glycerophosphate, and 10 $\mathrm{mM}$ benzamidine). After lysis in ice for $90 \mathrm{~min}$, insoluble materials were removed by centrifugation $\left(15,000 \mathrm{rpm}\right.$ at $4{ }^{\circ} \mathrm{C}$ for $\left.45 \mathrm{~min}\right)$, and protein concentrations of the resulting lysates were determined using a protein assay kit (Pierce, Perbio Science, Brebières, France). Proteins $(50 \mu \mathrm{g})$ were subjected to SDS-PAGE and transferred onto nitrocellulose membranes. Blots were blocked with 5\% nonfat milk and then incubated in the presence of appropriate primary antibodies (antiphosphorylated STAT-3 or anti-total STAT-3 from Cell Signaling; Ozyme, Saint Quentin en Yvelines, France) and secondary antibodies. Following nitrocellulose membrane washing, targeted proteins (about $92 \mathrm{kDa}$ ) were revealed using enhanced chemiluminescence reagents (Amersham Life Science, Les Ulis, France). The intensity of bands was quantified by using Scion Image Software and the p-STAT-3/t-STAT-3 ratios were calculated.

Statistical analysis. Statistical analysis was performed using (StatView Software, ver. 5) to detect significant intergroup differences. Values were expressed as means $\pm \mathrm{SE}$, and $P<0.05$ was considered statistically significant. 


\section{RESULTS}

Impact of the HF diet on body weight and energy intake of adult female rats. Adult females fed $\mathrm{C}$ or HF diet for $6 \mathrm{wk}$ showed similar body weights (BW) until day 17 (Fig. 1). From day 17 until mating period, BW became slightly but significantly higher $(5 \%)$ in HF than in control animals, reaching $285 \pm 4 \mathrm{~g}(n=13)$ and $272 \pm 3 \mathrm{~g}(n=12)$, respectively $(P<$ $0.05)$. The cumulative food intake measured for this 6-wk period was significantly smaller in $\mathrm{HF}(496 \pm 12 \mathrm{~g} / \mathrm{animal})$ than in $\mathrm{C}$ females (746 $\pm 18 \mathrm{~g} / \mathrm{animal})$. When taking into account the caloric density of each diet (Table 1), the daily energy intake was similar in the two groups with $67.5 \pm 1.4$ and $67.0 \pm 1.1 \mathrm{kcal}$ per rat for $\mathrm{C}$ and $\mathrm{HF}$ females, respectively.

Dams and pups until weaning. The BW gain of all dams until the end of the suckling period is shown on Fig. 1. During gestation, those fed the HF diet maintained their overweight compared with normally fed dams. After delivery, HF dams lost relatively more weight than did $\mathrm{C}$ dams, mainly during the second half of the lactation period, and then the body weight became identical in the two groups at the end of the weaning period.

After delivery, the number of pups per litter was similar for dams $(n=10)$ fed the high-fat diet $(11.4 \pm 0.8, n=123)$ and dams $(n=7)$ fed the low-fat diet $(13.1 \pm 0.7, n=92)$, with similar mean birth body weight (Fig. 2). After adjustment to 11 pups per litter, the mean body weight of suckling pups (aged $20 \pm 1$ days) was similar between the two groups (Fig. 2). When the eight experimental groups of pups were formed at weaning (28 days old), the body weight was significantly $(P<$ 0.0001 ) lower in males and females born to HF dams compared with those born to normally fed dams (Fig. 2).

Impact of the maternal diet on male and female offspring in the postweaning period. Table 2 shows body weight gain and food and energy intakes measured for the mid-4-wk (2nd to 5th wk) of the postweaning period, in the eight groups of male and female offspring (CCm, CCf, $\mathrm{CHm}, \mathrm{CHf}, \mathrm{HCm}, \mathrm{HCf}, \mathrm{HHm}$, HHf) named according to the postweaning diet (1st letter), maternal diet (2nd letter), and gender (3rd letter). In males, the daily energy intake was similar in the 4 groups, but the body weight gain was significantly higher in the $\mathrm{HCm}$ group than in the others. In females, the body weight gain was similar in the

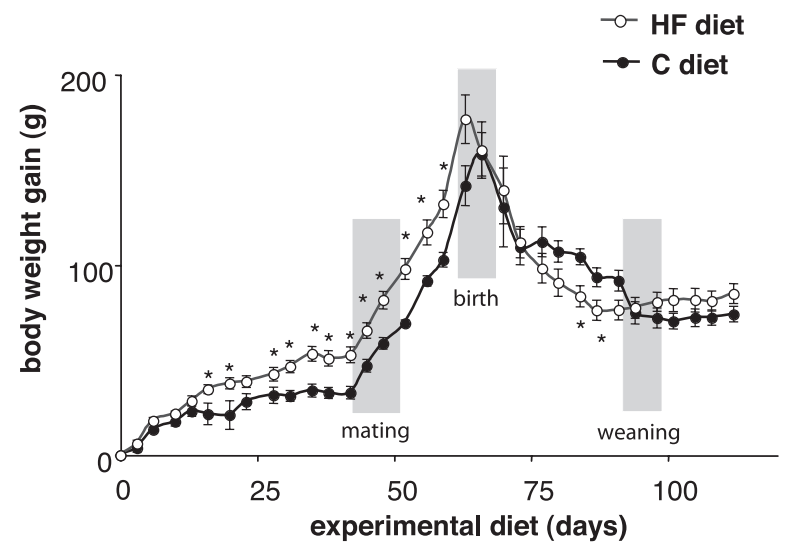

Fig. 1. Evolution of the body weight gain of dams fed the control (C) diet $(n=$ $7)$ or the high-fat (HF) diet $(n=10)$ for $6 \mathrm{wk}$ before mating, throughout gestation and lactation $(28$ days) and until the postweaning period $(* P<0.05)$.

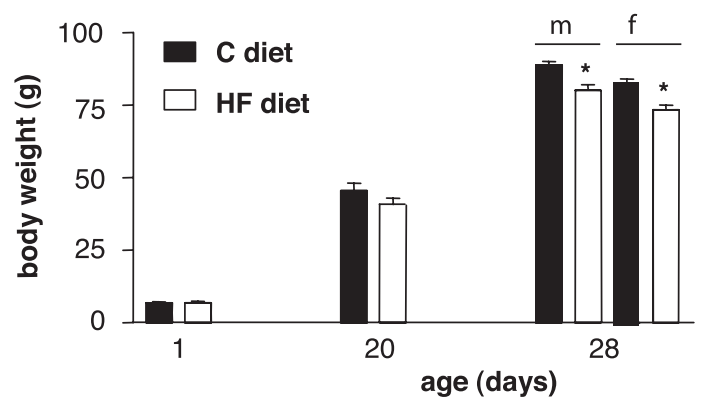

Fig. 2. Mean body weights of pups born to dams fed the $\mathrm{C}$ diet $(n=92)$ or the HF $(n=123)$ diet, measured at birth (day 1$)$, during lactation (20 days old), and at weaning ( 28 days old), according to the gender ( $35 \mathrm{C}$ males and $37 \mathrm{C}$ females; $36 \mathrm{HF}$ males and $37 \mathrm{HF}$ females, respectively). *Statistical difference $(P<0.05)$, as shown by a Student's $t$-test, between (male or female) animals born to dams fed the control or high-fat diet.

4 groups, as was the energy intake, except in the HCf group, which presented the smallest energy intake.

Impact of the maternal diet on adult male and female offspring. Body weights and physiological parameters, measured in the eight groups of adult offspring after overnight food deprivation are reported in Table 3 . In males, only rats fed the $\mathrm{HF}$ diet and born to control dams ( $\mathrm{HCm}$ group) showed a higher body weight $(+15 \%$ compared with other groups) with increased liver weight as expressed in percentage of body weight. In addition, they were hyperinsulinemic and hyperleptinemic, and they displayed an increased HOMA index value. In females, a more discrete overweight $(+5 \%)$ was observed only in rats from the HCf group, but a liver enlargement was observed in all rats fed the HF diet, irrespective of the maternal diet (HCf and HHf groups), compared with those fed the normal-fat diet (CCf and $\mathrm{CHf}$ ). However, $\mathrm{HCf}$ rats exhibited the highest plasma glucose levels, without significant changes in insulinemia, leptinemia, and HOMA index. Plasma triglyceride levels were similar in the four groups for each gender and were lower in females than in males. In both genders, the highest plasma cholesterol level was observed in normally fed offspring born to control dams (CCm and CCf groups).

Leptin-dependent STAT-3 phosphorylation in the hypothalamus. To compare the hypothalamic leptin sensitivity among the eight groups, STAT-3 phosphorylation levels were measured on the hypothalamic extracts from starved animals killed 30 min after leptin or saline IP bolus. In each group, STAT-3 phosphorylation levels were normalized to total STAT-3. The value 100 was attributed to the basal STAT-3 phosphorylation level (i.e., the p-STAT-3/total Stat-3 ratio measured in salineinjected animals), and a significant elevation of this ratio in leptin-injected animals was taken as an index of the central responsiveness toward leptin.

In male and female adult offspring fed the $\mathrm{C}$ diet and born to normally fed dams (CCm and $\mathrm{CCf}$ groups), leptin significantly $(P<0.005)$ increased STAT-3 phosphorylation by $63 \%$ and $122 \%$, respectively (Fig. 3). In offspring born to HF dams, STAT-3 phosphorylation in response to leptin was completely abolished (Fig. 3).

In male and female offspring fed HF diet and born to control or HF dams, leptin was unable to induce the phosphorylation of STAT-3 except in the HCf group, where leptin significantly $(P<0.005)$ increased STAT-3 phosphorylation by about $100 \%$ (Fig. 4). 
Table 2. Mean body weight gain and daily food and energy intakes in male and female offspring born to dams fed the $C$ or $H F$ diet and weaned onto the $C$ or HF diet, calculated for the mid-4-wk of the postweaning period

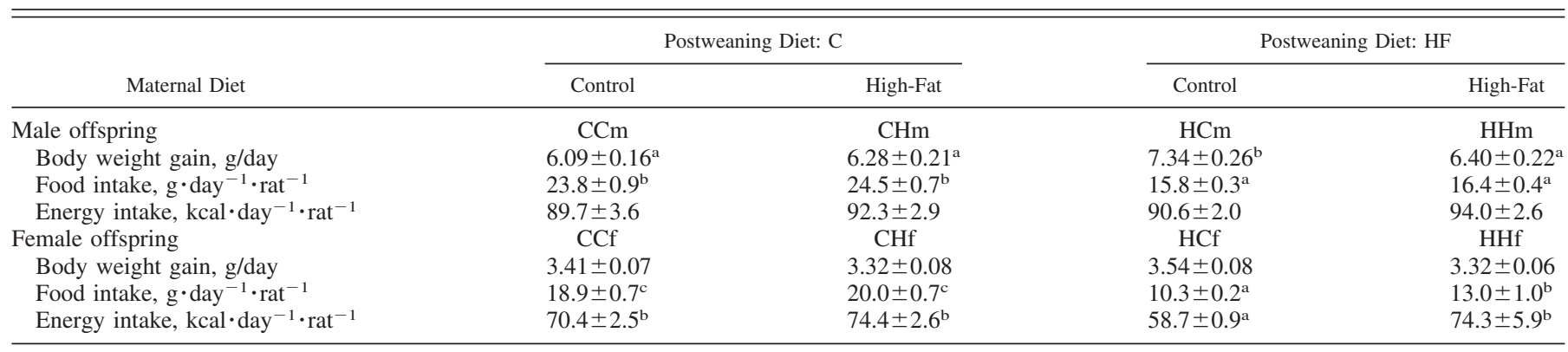

The statistical analysis was performed separately for male and female animals $(n=12$, except for $\mathrm{HCm}$ and $\mathrm{HHm}$ where one atypical animal in the initial groups was excluded). ${ }^{\mathrm{a}, \mathrm{b}, \mathrm{c}}$ Different superscript letters denote significant differences at $P<0.05$ by ANOVA and the Fisher post hoc test. Groups are named according to the postweaning diet ( $\mathrm{C}$ or $\mathrm{H}$ as 1 st letter for control or high-fat diet, respectively), maternal diet $(\mathrm{C}$ or $\mathrm{H}$ as $2 \mathrm{nd}$ letter), and gender ( $\mathrm{m}$ or $\mathrm{f}$ as $3 \mathrm{rd}$ letter, respectively).

\section{DISCUSSION}

In the present study, we show that adult females fed the high-fat diet adjusted their daily food intake to supply the same energy as that provided by the control diet. However, they displayed before mating a significant slight overweight, which lasted throughout gestation, but disappeared during the lactation period. In these conditions, neither the litter size nor the body weight of newborn rats was affected by the maternal diet, as previously reported in Wistar rats under analogous conditions (16). In addition, we show that the body weight of suckling pups (20 days old) did not differ according to the maternal diet, but at weaning (28 days old) and for both genders, pups reared by HF dams showed a lower body weight than those reared by control dams. This could be related to the significant body weight loss of HF dams during the second half of the lactation period, which might affect the energy supply of pups when kept in large litters. Indeed, under similar dietary conditions, but with litters reduced at birth $(n=6)$, pups reared by HF dams presented at weaning a higher body weight than those reared by chow-fed dams, with early signs of predisposition to obesity later in life as an effect of early overnutrition (16).

In agreement with data generally reported in Wistar rats, a sexual dimorphism was observed for body weight and various metabolic parameters such as plasma lipids, leptin, and insulin levels $(18,47)$. Thus, the results were analyzed separately for males and females (Tables 2 and 3) and for each gender; data obtained in rats born to normally fed dams and fed the $\mathrm{C}$ diet were taken as controls. When pups received the HF diet since weaning, only those born to $\mathrm{C}$ dams displayed a significant overweight after $6 \mathrm{wk}$, and this was more noticeable in males than in females $(17 \%$ and $5 \%$ of $\mathrm{BW}$, in $\mathrm{HCm}$ and $\mathrm{HCf}$ rats, respectively). In males, the overweight was associated with

Table 3. Final body weights and physiological parameters measured in eight groups of male and female offspring killed in a fasting state

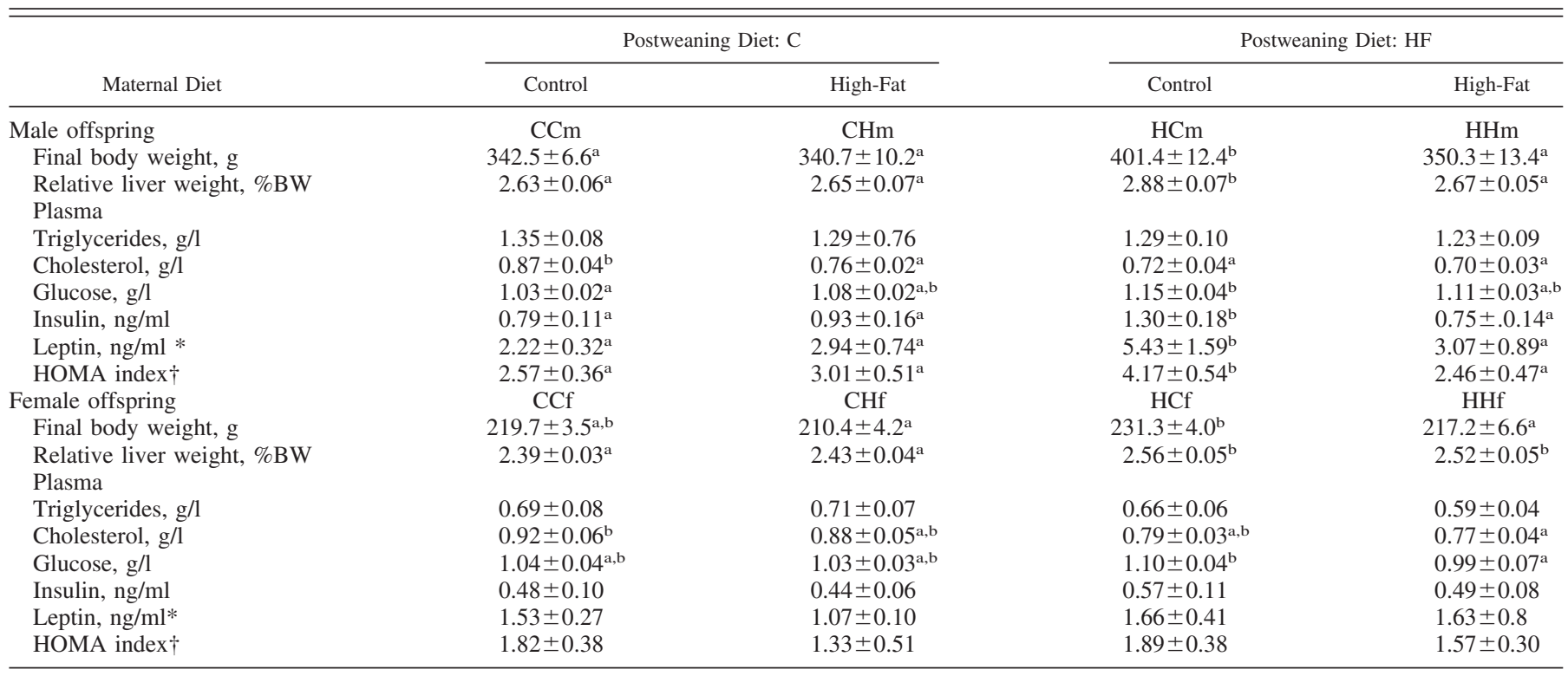

*Leptin concentration in control saline-injected animals ( $n=5$ or 6 per subgroup). $\dagger$ For calculation, see MATERIALS AND METHODS. The statistical analysis was performed separately for males and females $\left(n=9-12\right.$ per group) ${ }^{\text {a,b }}$ Different superscript letters denote significant differences at $P<0.05$ by ANOVA and the Fisher post hoc test. Same naming convention for group as in Table 2. HOMA, homeostatic model assessment. 


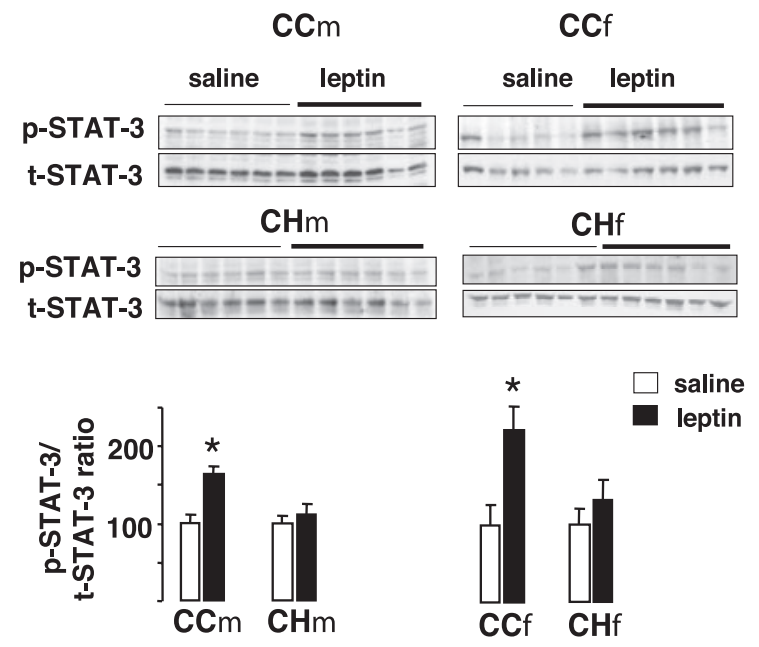

Fig. 3. Western blot analysis of phosphorylated and total STAT3 (p- and t-STAT3) in hypothalamic protein extracts from offspring weaned onto the $\mathrm{C}$ diet and born from dams fed either the $\mathrm{C}$ or the HF diet. Each group was named according to the postweaning diet (1st letter), maternal diet (2nd letter) and gender ( $\mathrm{m}$ or $\mathrm{f}$ as $3 \mathrm{rd}$ letter) and contained 12 rats injected either with saline ( $n=6$, except in CCf group: $n=5$ ) or with leptin $(n=6)$. *In each group, the sensitivity toward leptin was assessed by a significant elevation of the mean p-STAT3/t-STAT3 ratio in leptin-injected compared with saline-injected rats.

hyperleptinemia, hyperinsulinemia, and high HOMA value. Moreover, the relative enlargement of their liver reflects an early sign of the adverse effects of diets rich in saturated fatty acids (12). As could be expected, these animals exhibited also a hypothalamic leptin resistance, while leptin sensitivity was maintained in females (HCf group). This difference is most likely associated with the hyperleptinemia observed in males but not in females, and could be related to the gender difference in hypothalamic development $(3,30)$. Unexpectedly, $\mathrm{HHm}$ and HHf groups exhibited normal BW and metabolic parameters in adulthood, suggesting a long-term protection against the adverse effects of the HF diet as those observed in $\mathrm{HCm}$ and $\mathrm{HCf}$ groups. The difference between $\mathrm{HH}$ and $\mathrm{HC}$ groups could be attributed to the fact that $\mathrm{HH}$ rats were not subjected to diet transition. Interestingly at weaning, male and female pups of HF dams weighed less than those of control dams (Fig. 2), and this difference lasted until adulthood (Table 3: see $\mathrm{HHm}$ vs. $\mathrm{HCm}$, and HHf vs. HCf). This finding emphasizes the importance of environmental transitions in development $(14,18)$. Another example of a protective effect has been recently illustrated in Sprague-Dawley rats, as regards the cardiovascular dysfunction induced by this diet (23-25), as the endothelial dysfunction (but not hypertension) was prevented in offspring of dams fed a high-fat diet during pregnancy and suckling and raised on the same inappropriate diet. Such maternal imprinting, only due to maternal high-fat feeding, then contrasts with the perinatally acquired disposition to obesity and diabetes mellitus due to fetal and/or early postnatal hyperinsulinism induced by maternal diabetes mellitus during pregnancy or intrauterine growth retardation (32).

A possible explanation for the different responses to the HF diet according to the maternal diet may be drawn from the comparison of the daily weight gains and energy intakes (Table 2). On one hand, male pups from the 4 groups ingested similar energy amounts from the $\mathrm{C}$ or $\mathrm{HF}$ diet, but those born to HF dams and fed the HF diet (HHm group) gained less weight than their counterparts born to control dams ( $\mathrm{HCm}$ group). On the other hand, body weight gain was similar in the four groups of females, but those from the HHf group ingested relatively more energy than the HCf group. Therefore, the feed efficiency of the hypercaloric HF diet was much lower in both male and female offspring born to HF dams than in those born to control dams. These data suggest that maternal HF diet programmed an increased energy expenditure in pups when maintained on the same inappropriate diet until adulthood. It has been also shown that maternal high-fat feeding led to gender-related hypertension, cardiovascular, and endothelial dysfunction and even mitochondrial abnormalities in normally fed offspring, but without significant changes in body weight $(18,24,42)$. In the present study, independently of the gender and the postweaning diet (HH and $\mathrm{CH}$ groups), offspring of $\mathrm{HF}$ dams was characterized by normal corpulence and normal plasma leptin and insulin levels and no massive adiposity, at least until $10 \mathrm{wk}$ of age, but they were characterized by a defect of hypothalamic leptin signaling. The absence of hyperphagia, associated with significant BW gain in these leptin-resistant animals, could be due to other compensatory signaling pathways involving insulin receptor that may overcome this resistance. In addition, in this study we focused on STAT-3 signaling pathway, and it is well established that leptin may also signal through insulin receptor substrate/phosphatidylinositol-3-kinase pathways (4). The defective central leptin signaling programmed by the maternal HF diet may be opposed to that acquired by male offspring of normally fed dams ( $\mathrm{HCm}$ group), which became obese and insulin-resistant after HF feeding. Indeed, the status of the imprinted animals may be compared with that of offspring born to undernourished dams, which displayed a normal growth pattern as long as they were fed a commercial diet, but when switched to a HF diet in adulthood, showed marked weight gain $(17,43,46)$. In this last model, an early leptin treatment of the programmed offspring prevented their predisposition to become obese under hypercaloric conditions. It is

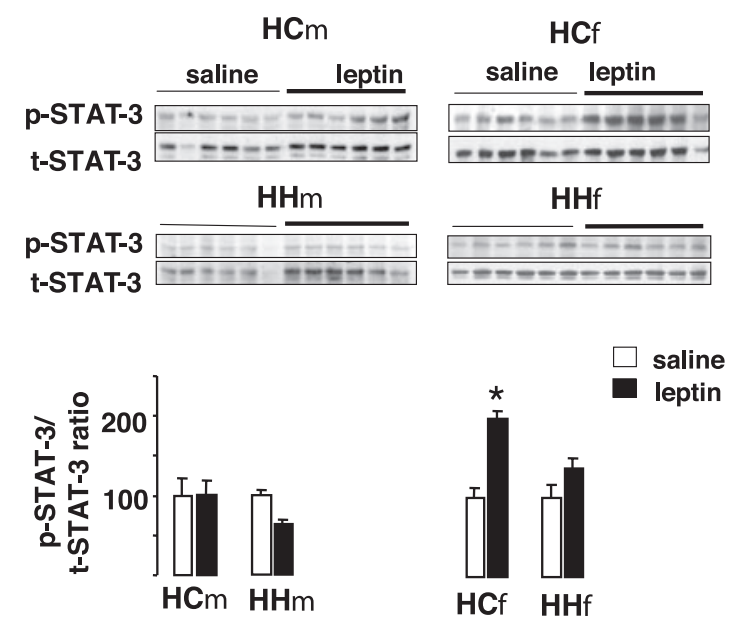

Fig. 4. Western blot analysis of p- and t-STAT3 in hypothalamic protein extracts from offspring weaned onto the HF diet and born from dams fed either the $\mathrm{C}$ or the HF diet. Each group was named according to the postweaning diet (1st letter), maternal diet (2nd letter), and gender ( $\mathrm{m}$ or $\mathrm{f}$ as $3 \mathrm{rd}$ letter) and contained 12 rats injected either with saline $(n=6)$ or with leptin $(n=6) 30$ min before death. *In each group, the sensitivity toward leptin was assessed by a significant elevation of mean p-STAT3/t-STAT3 ratio in leptin-injected compared with saline-injected rats. 
noteworthy that a leptin treatment of normally fed dams during late gestation and lactation reduced the susceptibility of their progeny to become obese and even increased energy expenditure in female offspring (41), while the treatment just at the end of lactation made their adult offspring more susceptible to overweight (26). Taking the results of the present study into account, further investigations are needed to determine whether hypothalamic leptin resistance programmed by the maternal HF diet in adult offspring raised on a normal diet ( $\mathrm{CHm}$ and $\mathrm{CHf}$ groups) will reduce or increase their susceptibility to develop obesity when switched to the HF diet or a more obesogenic diet later in life. Indeed, a first overfeeding model has been described in Wistar rats to induce maternal obesity and gestational diabetes mellitus associated with high hyperleptinemia and hyperinsulinemia in dams and pups (21).

In summary, this study in Wistar rats gives evidence of a metabolic imprinting of the progeny born to dams fed an inappropriate high-fat diet since $6 \mathrm{wk}$ before mating, which did not became overtly obese before gestation and even lost more body weight than control dams at the end of lactation. The long-term metabolic consequence of this maternal imprinting was an altered hypothalamic leptin signaling in male and female offspring which, however, looked as thin as controls in adulthood, even when weaned onto the HF diet.

\section{ACKNOWLEDGMENTS}

We thank Claire-Marie Vacher for critical reading of the manuscript and Joël Lefebvre for animal care.

\section{REFERENCES}

1. Armitage JA, Taylor PD, Poston L. Experimental models of developmental programming: consequences of exposure to an energy-rich diet during development. J Physiol 565: 3-8, 2005.

2. Arner P. The adipocyte in insulin resistance: key molecules and impact of the thiazolidiniones. Trends Endocrinol Metab 14: 137-145, 2003.

3. Arnold AP, Gorski RA. Gonadal steroid induction of structural sex differences in the central nervous system. Annu Rev Neurosci 7: 413-442, 1984.

4. Benomar Y, Wetzler S, Larue-Achagiotis C, Djiane J, Tome D, Taouis M. In vivo leptin infusion impairs insulin and leptin signalling in liver and hypothalamus. Mol Cell Endocrinol 242: 59-66, 2005.

5. Bjorbaek C, Uotani S, da Silva B, Flier JS. Divergent signaling capacities of the long and short isoforms of the leptin receptor. $J$ Biol Chem 272: 32686-32695, 1997.

6. Bouret SG, Draper SJ, Simerly RB. Trophic action of leptin on hypothalamic neurons that regulate feeding. Science 304: 108-110, 2004.

7. Desai M, Gayle D, Babu J, Ross MG. Programmed obesity in intrauterine growth-restricted newborns: modulation by newborn nutrition. Am J Physiol Regul Integr Comp Physiol 288: R91-R96, 2005.

8. Eckel RH, Grundy SM, Zimmet PZ. The metabolic syndrome. Lancet 365: 1415-1428, 2005.

9. Elmquist JK, Ahima R, Elias C, Elier JS, Saper CB. Leptin activates distinct projections from the dorsomedial and ventromedial hypothalamic nuclei. Proc Natl Acad Sci USA 95: 741-746, 1998.

10. Friedman JM, Halaas JL. Leptin and then regulation of body weight in mammals. Nature 395: 763-769, 1998.

11. Gallou-Kabani C, Junien C. Nutritional epigenomics of metabolic syndrome: new perspective against the epidemic. Diabetes 54: 1899-1906, 2005.

12. Gauthier MS, Favier R, Lavoie JM. Time course of the development of non-alcoholic hepatic steatosis in response to high-fat diet-induced obesity in rats. Br J Nutr 95: 273-281, 2006

13. Gertler A, Simmons J, Keisler DH. Preparation and characterization of recombinant ovine obese protein (leptin). FEBS Lett 422: 137-140, 1998

14. Gluckman PD, Hanson MA. Living the past: evolution, development, and patterns of disease. Science 305: 1733-1736, 2004.

15. Gorski JN, Dunn-Mynell AA, Hartman TG, Levin BE. Postnatal environment overrides genetic and prenatal factors influencing offspring obesity and insulin resistance. Am J Physiol Regul Integr Comp Physiol 291: R768-R778, 2006.

16. Guo F, Jen KL. High-fat feeding during pregnancy and lactation affects offspring metabolism in rats. Physiol Behav 57: 681-686, 1995.

17. Hales CN, Barker DJ. The thrifty phenotype hypothesis. Br Med Bull 60: 5-20, 2001.

18. Hanson MA, Gluckman PD. Developmental processes and the induction of cardiovascular function: conceptual aspects. J Physiol 15: 27-34, 2005.

19. Harding JE. The nutritional basis of fetal origins of adult disease. Int $J$ Epidemiol 30: 15-23, 2001.

20. Hofbauer KG. Molecular pathways to obesity. Int J Obes 26: 18-27, 2003.

21. Holemans K, Caluwaerts S, Poston L, Van Assche FA. Diet-induced obesity in the rat: a model for gestational diabetes mellitus. Am J Obstet Gynecol 190: 858-865, 2004.

22. Hubschle T, Thom E, Watson A, Roth J, Klaus S, Meyerhof W. Leptin-induced nuclear translocation of STAT-3 immunoreactivity in hypothalamic nuclei involved body weight regulation. J Neurosci 21: 2413-2424, 2001.

23. Khan IY, Taylor PD, Dekou V, Seed PT, Lakasing L, Graham D, Dominiczak AF, Hanson MA, Poston L. Gender-linked hypertension in offspring of lard-fed pregnant rats. Hypertension 41: 168-175, 2003.

24. Khan I, Dekou V, Hanson M, Poston L, Taylor P. Predictive adaptive responses to maternal high-fat diet prevent endothelial dysfunction but not hypertension in adult rat offspring. Circulation 110: 1097-1102, 2004.

25. Khan IY, Dekou V, Douglas G, Jensen R, Hanson MA, Poston L, Taylor PD. A high-fat diet during rat pregnancy or suckling induces cardiovascular dysfunction in adult offspring. Am J Physiol Regul Integr Comp Physiol 288: R127-R133, 2005.

26. Lins MC, de Moura EG, Lisboa PC, Bonomo IT, Passos MC. Effects of maternal leptin treatment during lactation on the body weight and leptin resistance of adult offspring. Regul Pept 127: 197-202, 2005.

27. Matthews DR, Hosker JP, Rudenski AS, Naylor BA, Treacher DF, Turner RC. Homeostasis model assessment: insulin resistance and betacell function from fasting plasma glucose and insulin concentrations in man. Diabetologia 7: 412-419, 1985.

28. Mcmillen IC, Robinson JS. Developmental origins of the metabolic syndrome prediction, plasticity, and programming. Physiol Rev 85: 571633, 2005.

29. Mokdad AH, Ford ES, Bowman BA, Dietz WH, Vinicor F, Bales VS, Marks JS. Prevalence of obesity, diabetes, and obesity-related health risk factors. JAMA 289: 76-79, 2003.

30. Mong JA, McCarthy MM. Ontogeny of sexually dimorphic astrocytes in the neonatal rat arcuate. Brain Res Dev Brain Res 139: 151-158, 2002.

31. Parsons TJ, Power C, Manor O. Fetal and early life growth and body mass index from birth to early adulthood in 1958 British cohort: longitudinal study. Br Med J 323: 1331-1335, 2001.

32. Plagemann A. Perinatal programming, and functional teratogenesis: impact on body weight regulation and obesity. Physiol Behav 86: 661-668, 2005.

33. Plagemann A. Perinatal nutrition and hormone-dependent programming of food intake. Horm Res 65: 83-89, 2006.

34. Ramsay JE, Ferrell WR, Crawford L, Wallace AM, Greer IA, Sattar N. Maternal obesity is associated with dysregulation of metabolic, vascular and inflammatory pathways. J Clin Endocrinol Metab 87: 4231-4237, 2002.

35. Ravelli GP, Stein ZA, Susser MW. Obesity in young men after famine exposure in utero and early infancy. N Engl J Med 295: 349-353, 1976.

36. Schwartz MW, Seeley RJ, Woods SC, Weigle DS, Campfield LA, Burn P, Baskin DG. Leptin increases hypothalamic pro-opiomelanocortin mRNA expression in the rostal arcuate nucleus. Diabetes 46: 2119 2123, 1997.

37. Simerly RB. Wired on hormones: endocrine regulation of hypothalamic development. Curr Opin Neurobiol 15: 81-85, 2005.

38. Sivitz WI, Walsh SA, Morgan DA, Thomas MJ, Haynes WG. Effects of leptin on insulin sensitivity in normal rats. Endocrinology 138: 3395 3401, 1997.

39. Speigelman BM, Flier JS. Obesity and regulation of energy balance. Cell 104: 531-543, 2001.

40. Stocker C, O'Dowd J, Morton NM, Wargent E, Sennitt MV, Hislop D, Glund S, Seckl JR, Arch JR, Cawthorne MA. Modulation of susceptibility to weight gain and insulin resistance in low birthweight rats by treatment of their mothers with leptin during pregnancy and lactation. Int J Obes Relat Metab Disord 28: 129-136, 2004. 
41. Stocker CJ, Wargent E, O'dowd J, Cornick C, Speakman JR, Arch JR, Cawthorne MA. Prevention of diet-induced obesity and impaired glucose tolerance in rats following administration of leptin to their mothers. Am J Physiol Regul Integr Comp Physiol 292: R1810-R1818, 2007.

42. Taylor PD, McConnell J, Khan IY, Holemans K, Lawrence KM, Asare-Anane H, Persaud SJ, Jones PM, Petrie L, Hanson MA, Poston L. Impaired glucose homeostasis and mitochondrial abnormalities in offspring of rats fed a fat-rich diet in pregnancy. Am J Physiol Regul Integr Comp Physiol 288: R134-R139, 2005.

43. Vickers MH, Breier BH, Cutfield WS, Hofman PL, Gluckman PD. Fetal origins of hyperphagia, obesity, and hypertension and postnatal amplification by hypercaloric nutrition. Am J Physiol Endocrinol Metab 279: E83-E87, 2000.

44. Vickers MH, Reddy S, Ikenasio BA, Brier BH. Dysregulation of the adipo-insular axis: a mechanism for the pathogenesis of hyperleptinemia and adipogenic diabetes induced by fetal programming. J Endocrinol 170: 323-332, 2001.

45. Vickers MH, Breier BH, McCarthy D, Gluckman PD. Sedentary behavior during postnatal life is determined by the prenatal environment and exacerbated by postnatal hypercaloric nutrition. Am J Physiol Regul Integr Comp Physiol 285: R271-R273, 2003.

46. Vickers MH, Gluckman PD, Coveny AH, Hofman PL, Cutfield WS, Gertler A, Breier BH, Harris M. Neonatal leptin treatment reverses developmental programming. Endocrinology 46: 4211-4216, 2005.

47. Zambrano E, Bautista CJ, Deas M, Martinez-Samayoa PM, Gonzalez-Zamorano M, Ledesma H, Morales J, Larrea F, Nathanielsz PW. A low maternal protein diet during pregnancy and lactation has sex- and window of exposure-specific effects on offspring growth and food intake, glucose metabolism and serum leptin rat. J Physiol 571: 221-230, 2006

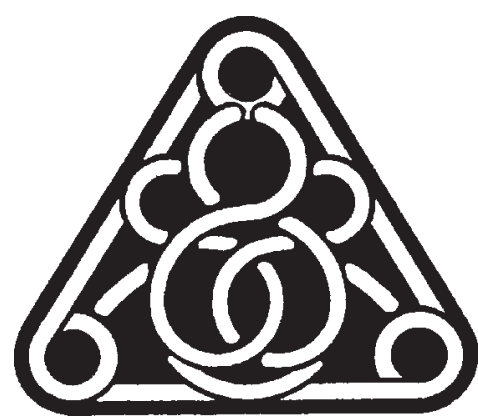

